\title{
Identificação de concepções antropomórficas, teleológicas e vitalistas entre participantes de uma reunião anual da SBBq
}

\author{
Identification of anthropomorphic, teleological and vitalist conceptions amongst participants of an annual \\ meeting of SBBq
}

Ariane Leites Larentis ${ }^{1,2^{*}}$, Lúcio Ayres Caldas ${ }^{1,3}$, Manuel Gustavo Leito Ribeiro ${ }^{1,4}$, Marcelo Hawrylak Herbst ${ }^{1,5}$, Tomás Coelho Garcia ${ }^{1,6}$, Letícia Labati Terra ${ }^{1}$, Rodrigo Volcan Almeida ${ }^{1,7}$

${ }^{1}$ Grupo Interinstitucional e Interdisciplinar de Estudos em Epistemologia (www.epistemologia.ufrj.br)

${ }^{2}$ Centro de Estudos da Saúde do Trabalhador e Ecologia Humana, Escola Nacional de Saúde

Pública(ENSP/CESTEH), Fundação Oswaldo Cruz (Fiocruz), Rio de Janeiro, RJ, Brasil

${ }^{3}$ Grupo de Pesquisa de microscopia Aplicada às Ciências da Vida, Instituto Nacional de Metrologia, Qualidade e Tecnologia (INMETRO), Duque de Caxias, Rio de Janeiro, Brasil

${ }^{4}$ Departamento de Biologia Celular e Molecular, Instituto de Biologia (IB), Universidade Federal Fluminense (UFF), Niterói, RJ, Brasil

5D Instituto de Química, Instituto de Ciências Exatas (ICE), Universidade Federal Rural do Rio de Janeiro (UFRRJ), Seropédica, RJ, Brasil

${ }^{6}$ Instituto de Estudos Sociais e Políticos (IESP), Universidade Estadual do Rio de Janeiro (UERJ), Rio de Janeiro, RJ, Brasil

${ }^{7}$ Departamento de Bioquímica, Instituto de Química (IQ), Universidade Federal do Rio de Janeiro (UFRJ), Rio de Janeiro, RJ, Brasil

*e-mail: arianelarentis@fiocruz.br

\section{Resumo}

Neste trabalho, buscou-se identificar obstáculos epistemológicos entre os presentes na XXXIX Reunião Anual da Sociedade Brasileira de Bioquímica e Biologia Molecular (SBBq). Um questionário com perguntas e excertos de artigos científicos de revistas de alto fator de impacto foi respondido por 97 presentes (39 estudantes de iniciação científica, 42 pós-graduandos e 16 professores e pesquisadores). A partir da noção de obstáculo epistemológico proposta por Bachelard, foi possível identificar concepções vitalistas (animismo), concepções teleológicas dos processos evolutivos, em afirmações como a existência de objetivos/finalidades na adaptação dos organismos, assim como uma visão antropomórfica dos processos biológicos em avaliação, tanto nas respostas às perguntas como na aceitação ou não identificação destes obstáculos nos excertos. Verificou-se a presença de figuras de linguagem, metáforas e analogias (obstáculo verbal) na explicação da evolução e do sistema imune, também presentes nos excertos dos artigos.

Palavras-chave: antropomorfismo; teleologia; vitalismo.

\begin{abstract}
The aim of this work was to identify epistemological obstacles amongst participants of XXXIX Annual Meeting of Brazilian Society of Biochemistry and Molecular Biology. A questionnaire with selected excerpts of scientific papers from high impact factor journals was answered by 97 participants of this annual meeting (39 under-graduates, 42 graduate students, and 16 professors and researchers). From Bachelard's notion of teleological obstacle, it was possible to identify vitalist conceptions (animism), teleological approaches of the evolution processes, expressed in apologies of immanent purposes in organisms' adaptation, and an anthropomorphic vision of the biological processes under evaluation in the answers and also in the acceptance or not recognition of these obstacles in the excerpts. The presence of figures of speech, metaphors and analogies (verbal obstacle) were verified in explaining the evolution and the immune system, also present in the excerpts.
\end{abstract}

Keywords: anthropomorphism; teleology; vitalism. 
Identification of anthropomorphic, teleological and vitalist conceptions amongst participants of an annual meeting of SBBq

\section{Introdução}

A Bioquímica é uma importante área do conhecimento das ciências biológicas e químicas, fazendo parte do currículo básico de vários cursos de saúde e de alguns cursos de Engenharia nas universidades. Devido à grande complexidade das vias metabólicas, à enorme terminologia de enzimas e moléculas reguladoras e ao grau de pensamento abstrato exigido para sua compreensão, é recorrente que educadores utilizem o emprego de recursos técnicos e uma linguagem que facilitem o aprendizado e atraiam a atenção por parte dos estudantes.

O uso de argumentos finalistas, antropomórficos e vitalistas, além de linguagem metafórica e analogias, é legitimado pela maioria dos educadores e reforçado por sua presença em artigos científicos da área, publicados em revistas indexadas e de impacto considerável. No entanto, é importante questionarmos quando essas ferramentas são usadas apenas como apoio à compreensão deste campo científico e como figuras de linguagem, ou se elas estão presentes entre estudantes, professores e pesquisadores na forma de conceitos estabelecidos e evidenciando concepções errôneas acerca do conhecimento científico, i. e., se elas estão atuando como obstáculos epistemológicos.

A partir de sua noção de Obstáculo Epistemológico, apresentada em 1938 em "A Formação do Espírito Científico", Gaston Bachelard discute que é em termos de obstáculos no próprio ato de conhecer que o problema do conhecimento científico deve ser colocado, como causas de estagnação e até de regressão das ciências. Bachelard propõe que "o ato de conhecer dá-se contra um conhecimento anterior, destruindo conhecimentos mal estabelecidos (...)" [1]. Um obstáculo epistemológico pode ser compreendido como uma forma de conhecimento que resiste às mudanças devido ao seu poder explicativo ou, em outras palavras, devido à sua posição conceitual num dado sistema de conhecimentos [2]. Entre os obstáculos epistemológicos identificados por Bachelard (1996) estão o animismo e o conhecimento unitário e pragmático.

Bachelard caracteriza o obstáculo animista ao analisar a interferência de noções presentes no campo da Biologia ao entendimento de fenômenos da Física e da Química. Para Bachelard, a intuição da vida impede um estudo objetivo dos fenômenos físicos: " $A$ Vida é uma palavra mágica". O obstáculo animista trata a "vida como um dado claro e geral" [1]. No campo da Física, o animismo funciona ao nível das imagens; porém o mesmo não ocorre na Biologia. Michel Pêcheux, em "Sobre a História das Ciências" [3] 
Identification of anthropomorphic, teleological and vitalist conceptions amongst participants of an annual meeting of SBBq

discute que o animismo toma em Biologia o nome de vitalismo. Segundo Pêcheux, o papel desempenhado pelo animismo nas ciências físicas não é o mesmo que o do vitalismo na Biologia. Ao discutir o vitalismo no campo das ciências biológicas, Pêcheux mostra que ele representa uma posição conceitual nesta ciência. Neste trabalho adotaremos esta última concepção nas discussões sobre o obstáculo animista.

O obstáculo do conhecimento unitário e pragmático descrito por Bachelard alerta sobre o perigo de se recorrer à unidade da natureza e utilidade dos fenômenos naturais ao tentar explicá-los: "Em todos os fenômenos, procura-se a utilidade humana, não só pela vantagem que pode oferecer, mas como princípio de explicação. Encontrar uma utilidade é encontrar uma razão." [1].

Na prática científica, este obstáculo revela a tendência a uma concepção finalista e, portanto, teleológica dos fenômenos. A teleologia é considerada por Ernst Mayr como a ideologia que mais influenciou a Biologia: "talvez nenhuma outra ideologia tenha influenciado a biologia mais profundamente que o pensamento teleológico" [4]. Investigando as concepções de Bachelard e Mayr, propusemos a noção de obstáculo teleológico [5]. O aspecto antropomórfico do obstáculo unitário e pragmático destacado neste trabalho corresponde a um desenvolvimento teórico da concepção bachelardiana de obstáculo epistemológico, objeto de estudos a que nosso grupo de pesquisas tem se dedicado.

Alguns autores, não utilizando como referencial teórico a epistemologia de Bachelard, têm pesquisado a importância do animismo, da teleologia e do antropomorfismo no ensino de ciências [6-9]. Segundo Tamir e Zohar [7], a teleologia se refere a casos nos quais os fins são usados como explicações para a forma como certas estruturas são construídas, ou para a maneira como certas funções são exercidas. Estes autores também argumentam que a explicação teleológica implica a atribuição de consciência a seres não humanos, ou a diferentes órgãos, sendo desta forma, uma maneira enganadora de se entender cientificamente o fenômeno. Por outro lado, antropomorfismo é considerado como a atribuição de um racional humano a seres não humanos, assim Tamir e Zohar [7] consideram que a teleologia pode ser considerada como um caso especial de antropomorfismo.

Em um trabalho anterior [10], foi possível identificar concepções vitalistas e teleológicas entre pós-graduandos da área de Bioquímica. Esses resultados provocaram o questionamento se essas concepções eram características daquele grupo investigado 
Identification of anthropomorphic, teleological and vitalist conceptions amongst participants of an annual meeting of SBBq

ou poderiam estar presentes em um público mais abrangente. Pela importância destes obstáculos ao desenvolvimento do conhecimento científico na área de Bioquímica e ciências correlatas, neste trabalho buscou-se identificar as concepções vitalistas (animismo), antropomórficas e teleológicas entre pesquisadores participantes da XXXIX Reunião Anual da Sociedade Brasileira de Bioquímica e Biologia Molecular (SBBq), por ser o principal congresso brasileiro da área.

\section{Materiais e Métodos}

Este trabalho constitui um aprofundamento (prático e teórico) do estudo apresentado de forma resumida no VIII Encontro Nacional de Pesquisa em Educação em Ciências - ENPEC [11]. Os questionários foram distribuídos aleatoriamente aos inscritos na XXXIX Reunião Anual da SBBq (18 a 21 de maio de 2010, Foz do Iguaçu, Paraná) em palestras, sessões de pôsteres, no credenciamento e recebimento de auxílio.

O questionário foi elaborado com o objetivo de identificar obstáculos epistemológicos e verificar o nível de concordância/discordância com afirmativas e excertos baseados em noções do senso comum ou extraídos de artigos científicos de revistas de qualidade reconhecida e elevado fator de impacto (os títulos das revistas foram omitidos nos questionários para evitar sugestionar as respostas).

Após cada um dos excertos (Quadro 1), os participantes deveriam assinalar o seu nível de concordância com o texto, escolhendo uma das seguintes alternativas, elaboradas com base na escala de Likert [12]: Discordo; Discordo parcialmente; Não sei; Concordo parcialmente; Concordo. Além disso, o questionário estimulava os participantes a justificar suas respostas perguntando "Por quê?" após a escala de alternativas. As respostas dos questionários, transcritas sem correções, estão apresentadas em quadros em documento suplementar. 
Identification of anthropomorphic, teleological and vitalist conceptions amongst participants of an annual meeting of $S B B q$

Quadro 1. Excertos baseados em noções do senso comum ou extraídos de artigos publicados em revistas de qualidade reconhecida e elevado fator de impacto. Os excertos foram apresentados na forma de um questionário e os participantes deveriam assinalar o grau de concordância com cada um deles. $\mathrm{O}$ excerto (1) é de autoria de Ernst Mayr [4], definindo a evolução como um processo não teleológico e foi inserido no questionário como forma de um controle sobre as demais respostas.

1) "A evolução (é) com freqüência considerada um processo teleológico porque levaria a "melhoramento" ou "progresso". (...) Decerto é a seleção natural um processo de otimização, mas não tem meta definida, e, considerando o número de restrições e a freqüência de eventos aleatórios, seria por demais equivocado chamá-la de teleológica. (...) A seleção natural lida com propriedades de indivíduos de determinada geração; ela simplesmente carece de uma meta de longo alcance, embora assim pareça quando se olha para trás, abrangendo uma longa série de gerações." [Mayr, 2005]

2) Sobre a "hipótese de manipulação": "É bem conhecido que a infecção com T. gondii pode afetar a cognição e o comportamento de roedores. (...) Estudos mais recentes levaram os pesquisadores a formular a hipótese de manipulação. Esta hipótese estabelece que o parasita pode alterar o comportamento de seus hospedeiros para aumentar sua taxa de transmissão. (...) Em 1994, Webster et al. publicaram estudos demonstrando que ratos infectados com T. gondii foram mais ativos e menos neofóbicos à urina de gatos do que os controles; as respostas à urina de animais não predadores tais como coelhos não foram alteradas pela infecção toxoplasmática. Estas alterações levariam o rato a ser mais facilmente devorado pelo gato, assim completando o ciclo de vida do T. gondii e sendo um exemplo da hipótese de manipulação." [Yolken et al., 2009; tradução nossa] [13]

3) "O objetivo de todos os organismos é viver".

4) Sobre a ideia de "corrida armamentista": "Muitas bactérias patogênicas escondem-se e crescem em compartimentos intracelulares ligados à membrana, chamados fagossomos, onde elas são protegidas do sistema imune e ainda recebem nutrientes da célula infectada. Esta situação coloca um problema para o hospedeiro. Desta forma a célula hospedeira toma medidas para destruir o patógeno, o qual, obviamente, tenta se defender. Em uma clássica "corrida armamentista" evolucionária, ambos, patógeno e células hospedeiras têm desenvolvido um arsenal de armas, e esta corrida certamente não está terminada ainda." [Kuijl e Neefdjes, 2009; tradução nossa] [14]

5) Sobre a ideia de "patógenos traiçoeiros": "Parasitas intracelulares usam várias estratégias para invadir as células e subverter as rotas de sinalização celular e, assim, ganhar uma posição contra as defesas do hospedeiro. Entrada eficiente, habilidade para explorar nichos intracelulares, e persistência fazem destes parasitas patógenos traiçoeiros." [Sibley et al., 2004; tradução nossa] [15]

6) "Os microrganismos têm personalidade."

Foram coletados 97 questionários respondidos: 39 por estudantes de iniciação científica (ICs), 42 por pós-graduandos (PGs) e 16 por professores e pesquisadores (PPs) com formação em Bioquímica e áreas correlatas de universidades e institutos de pesquisa distribuídos pelo país (Fiocruz, Instituto Butantan, UEM, UEPG, UFABC, UFAL, UFBA, UFC, UFES, UFMA, UFOP, UFPE, UFPR, UFRGS, UFRJ, UFRN, UFRRJ, UFS, UFSC, UFSJ, UMC, UnB, UNESP, Unicamp, Unifesp, UNIRIO, UNIOESTE, UPE, UPMUniversidade Presbiteriana Mackenzie, USP). Os cursos de graduação identificados foram Agronomia/Ciências Agrícolas, Biologia/Ciências Biológicas, Bioengenharia, Biomedicina, Bioquímica, Biotecnologia, Educação Física, Engenharia Agronômica, Farmácia, Física, Medicina, Medicina Veterinária, Microbiologia/Imunologia, Nutrição, Odontologia e Química, incluindo bacharelado, licenciatura e cursos para tecnólogos. Dos participantes, dois pós-graduandos eram da Universidad Nacional de Córdoba, Argentina. 
Identification of anthropomorphic, teleological and vitalist conceptions amongst participants of an annual meeting of SBBq

Este trabalho faz parte de uma linha de pesquisa do Grupo Interinstitucional e Interdisciplinar de Estudos em Epistemologia (GI2E2 - www.epistemologia.ufrj.br), integrado atualmente por docentes e pesquisadores de diferentes instituições do Estado do Rio de Janeiro (Fiocruz, UFRJ, UFF, UFRRJ e UERJ) que foi avaliada pelo Comitê de Ética em Pesquisa da ENSP/Fiocruz e aprovada sob o número CAAE 14095313.0.0000.5240.

Não foi empregado Termo de Consentimento Livre e Esclarecido (TCLE), pois o estudo foi conduzido de forma cega, não sendo possível aos pesquisadores terem acesso aos dados pessoais e preservando a identidade de todos os participantes, com garantia de anonimato e confidencialidade das respostas. Assim, os questionários foram anônimos e os resultados foram analisados em conjunto e não individualmente ou focando alguma instituição ou método de ensino específico. Esta abordagem foi escolhida porque o $\mathrm{Gl}_{2} \mathrm{E}_{2}$ não tem como objeto de pesquisa a implementação de estudos cognitivos individuais, mas sim do processo de desenvolvimento das ciências e a investigação dos obstáculos epistemológicos a elas relacionados, que ocorre de forma histórica e coletiva.

\section{Resultados}

Foram identificadas concepções antropomórficas, teleológicas e vitalistas nas repostas ao questionário em todas as três categorias, independente da área de formação, da universidade ou do tempo de atuação em Bioquímica.

\subsection{Evolução segundo Ernst Mayr}

Com relação a este excerto, o perfil de respostas entre as categorias foi diverso, com significativo número de respostas "Não sei" entre estudantes de iniciação científica (aproximadamente $36 \%$ ) e pós-graduandos (12\%). Entretanto nenhum PP afirmou não saber opinar sobre a frase (Figura 1). Essa diversidade ocorreu possivelmente devido à maior ou menor familiaridade com os termos e conceitos presentes no excerto. 
Identification of anthropomorphic, teleological and vitalist conceptions amongst participants of an annual meeting of $S B B q$

\section{Evolução segundo Mayr}

$\begin{array}{lll}\square \text { Não Respondeu } & \square \text { Concorda } & \mathbb{\$} \text { Concorda Parcialmente } \\ \square \text { Não Sabe } & \square \text { Discorda Parcialmente } & \text { Discorda }\end{array}$

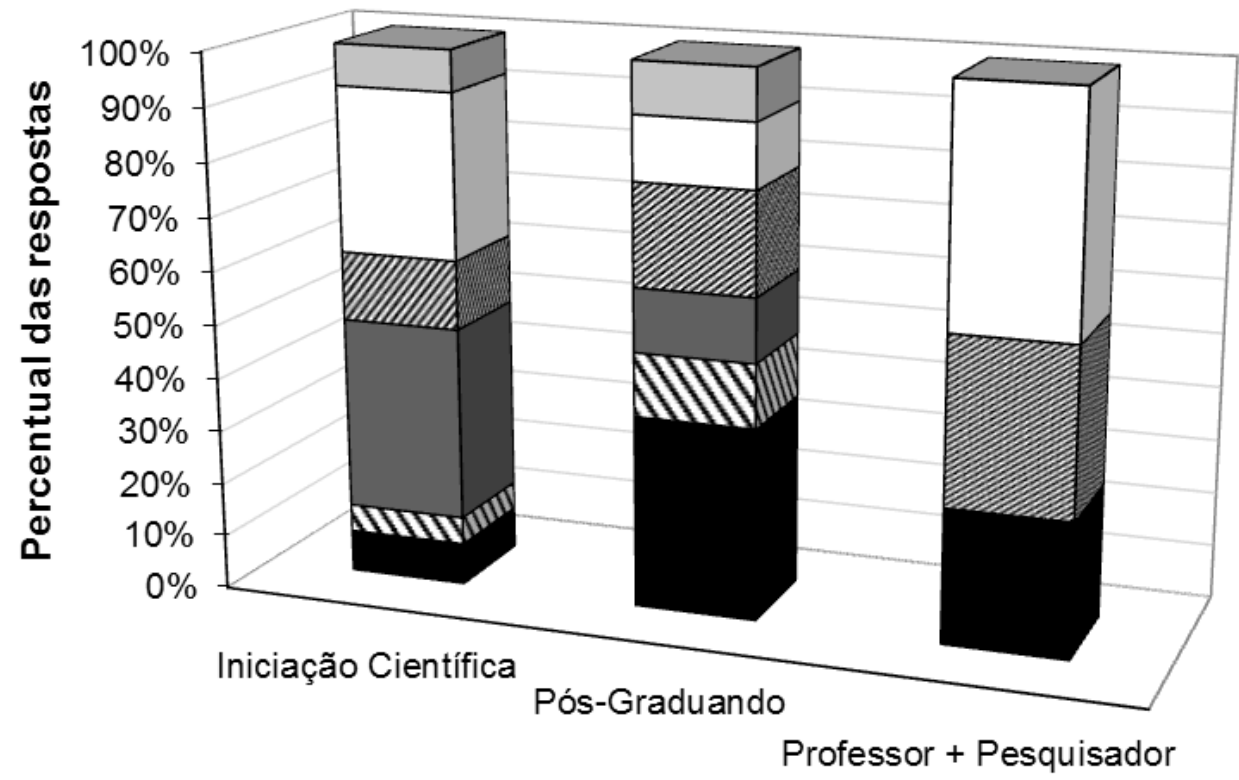

Figura 1. Respostas (\%) ao excerto "A evolução (é) com frequência considerada um processo teleológico porque levaria a "melhoramento" ou "progresso". (...) Decerto é a seleção natural um processo de otimização, mas não tem meta definida, e, considerando o número de restrições e a frequência de eventos aleatórios, seria por demais equivocado chamá-la de teleológica. (...)A seleção natural lida com propriedades de indivíduos de determinada geração; ela simplesmente carece de uma meta de longo alcance, embora assim pareça quando se olha para trás, abrangendo uma longa série de gerações." [4].

Algumas respostas discursivas dos ICs e PGs são explícitas: "Não entendi a frase."; "Não sei o que é teleológico!"; "Não sei. Série de terminologias abstratas (...)". Contudo, há um alto índice de concordância entre os ICs: 43,6\% afirmaram concordar, mesmo manifestando objeções quanto à frase (caso do item "concorda parcialmente"). Conforme análise das demais respostas é possível que a autoridade de Mayr na área tenha induzido ao maior nível de concordância neste excerto, como explicitado por um estudante: "Mayr é mestre, e a evolução é fato".

Das respostas que concordaram com o excerto de Mayr entre os estudantes de iniciação científica, destacam-se: "Concordo. Eventos aleatórios são extremamente comuns no tempo do universo (...)" e "Concordo parcialmente. A evolução natural não tem como prevê (sic) o futuro das espécies, qual sobreviverá, porém, quando olhamos para trás, vimos que muitas gerações foram extintas e as resistentes (que conseguiram sobreviver) permaneceram.". 
Identification of anthropomorphic, teleological and vitalist conceptions amongst participants of an annual meeting of SBBq

Entre os pós-graduandos destacamos os que concordam com a frase $(31 \%)$ : "Concordo parcialmente. Para mim o nome evolução é equivocado para a teoria. A origem da palavra evoluir significa melhorar. E a teoria não é essa..."; "Concordo. A evolução não leva necessariamente a uma melhora ou objetiva um fim específico. É aleatória. E é a seleção natural que faz com que determinadas características perdurem ou sejam eliminadas.".

O maior índice de discordância foi entre os PGs: $47,6 \%$ dos estudantes discordaram. A análise das justificativas expostas por alguns PGs indica que, ao tentar explicar suas discordâncias, os alunos demonstraram não ter compreendido corretamente o excerto de Mayr. Como exemplo, podemos citar: "Discordo parcialmente. Não acho que a seleção natural tenha uma meta de longo alcance, e sim uma meta evolutiva (...)". No excerto Mayr afirma que a seleção "carece de uma meta de longo alcance", o que seria incompatível com a discordância do aluno. Após analisar as justificativas, consideramos que respostas deste tipo refletem o fato de que possam ter ocorrido erros de interpretação do excerto. Dois outros exemplos de discordância são apresentados a seguir: "A idéia (sic) de melhoramento é errada.

A seleção natural não tem uma meta." e "A evolução não é um processo de melhoramento, ou progresso. Se isso ocorrer é muito bom, porém a evolução é uma mudança (sic) ela não é direcionada, ela apenas ocorre". Essas opiniões demonstram a dificuldade na compreensão/não familiaridade com os termos empregados no excerto. Identificamos essa dificuldade ao perceber que algumas respostas na escala de Likert concordam com o texto, mas ao justificar os alunos explicitam conceitos completamente opostos: "Toda evolução tem como principal objetivo a melhora, em especial a sobrevivência e para manutenção da espécie."; "A evolução resulta de eventos aleatórios que por seleção natural conferem um 'objetivo', se olharmos para trás (sic)." (grifos nossos).

Apenas 25\% dos PPs discordaram do trecho, mostrando uma identificação maior com o autor e suas ideias. Os professores e pesquisadores que concordaram (75\%) enfatizaram o questionamento à teleologia comumente associada aos processos evolutivos. Destacamos as respostas: "Os seres vivos constituem um produto evolucionário à (sic) cada geração, sobrevivendo ou sucumbindo a adversidades."; "Mudanças só são observadas após um longo período, às vezes não são claras. Mas após várias gerações são observadas.". Entre os que discordaram (25\%), estão algumas 
Identification of anthropomorphic, teleological and vitalist conceptions amongst participants of an annual meeting of SBBq

respostas que explicitam um pensamento teleológico e vitalista, como: "A evolução não é retilínea, ela é regida por uma força que prima pela sobrevivência (...)" (grifo nosso). Do ponto de vista científico, materialista, que força seria esta que prima pela sobrevivência? Mayr (2005) discute que, para os vitalistas, as manifestações de vida em um organismo são controladas por uma "força vital" (vis vitalis), o que, na terminologia bachelardiana constitui-se como um obstáculo epistemológico [10].

Apesar da discordância formal com o excerto, outras respostas dos professores questionaram a teleologia no processo de seleção natural, como: "Seleção natural, num determinado ambiente um indivíduo pode se sobressair (sic), porém não necessariamente o 'melhor', até (sic) porque o fator que causa a seleção não precisa ser permanente. Assim o mais adaptado se mantém (sic), não o 'melhor'."; "A teleologia fundamenta-se em um projeto transcendental ao jogo dos acasos fortuitos das mutações aleatórias. Portanto, não há objetivos ou alvos a serem atingidos.".

\subsection{Hipótese de manipulação}

Dos ICs participantes da pesquisa, 35,9\% não soube opinar sobre a frase da "hipótese da manipulação", contra $23,8 \%$ dos PGs e $12,5 \%$ dos PPs. Contudo, a maior parte das respostas a este excerto foi de concordância (ou concordância parcial), como mostrado na Figura 2, sem questionamento das concepções vitalista e teleológica implícitas na "hipótese de manipulação", ou pelo menos, da presença de um obstáculo verbal que deixa margem a uma interpretação de intencionalidade no processo descrito pelos autores do artigo.

O grau de discordância total e parcial quanto à frase ficou em $23 \%$ para os ICs, $19 \%$ para os PGs e $25 \%$ para os PPs. Ao mesmo tempo a concordância foi alta para os PPs: $62,5 \%$ dos professores-pesquisadores concordaram com essa assertiva, enquanto apenas $35,8 \%$ dos ICs e $45,2 \%$ dos PGs opinaram a favor. Contudo, dos PGs que concordaram parcialmente, alguns questionaram a intencionalidade do parasita, como pode ser verificado no comentário: "Pois não acredito que o $T$. gondii tenha desenvolvido esta 'artimanha' com o intuito específico que conhecemos, o acaso favoreceu esta estratégia dele, e provavelmente muitas outras deixaram de ser usadas pois não conferiam nenhuma vantagem, prevalecendo esta.", discutindo a estratégia como tendo sido favorecida pelo acaso por ser vantajosa para o T. gondii. 
Identification of anthropomorphic, teleological and vitalist conceptions amongst participants of an annual meeting of $S B B q$

\section{Hipótese de manipulação}

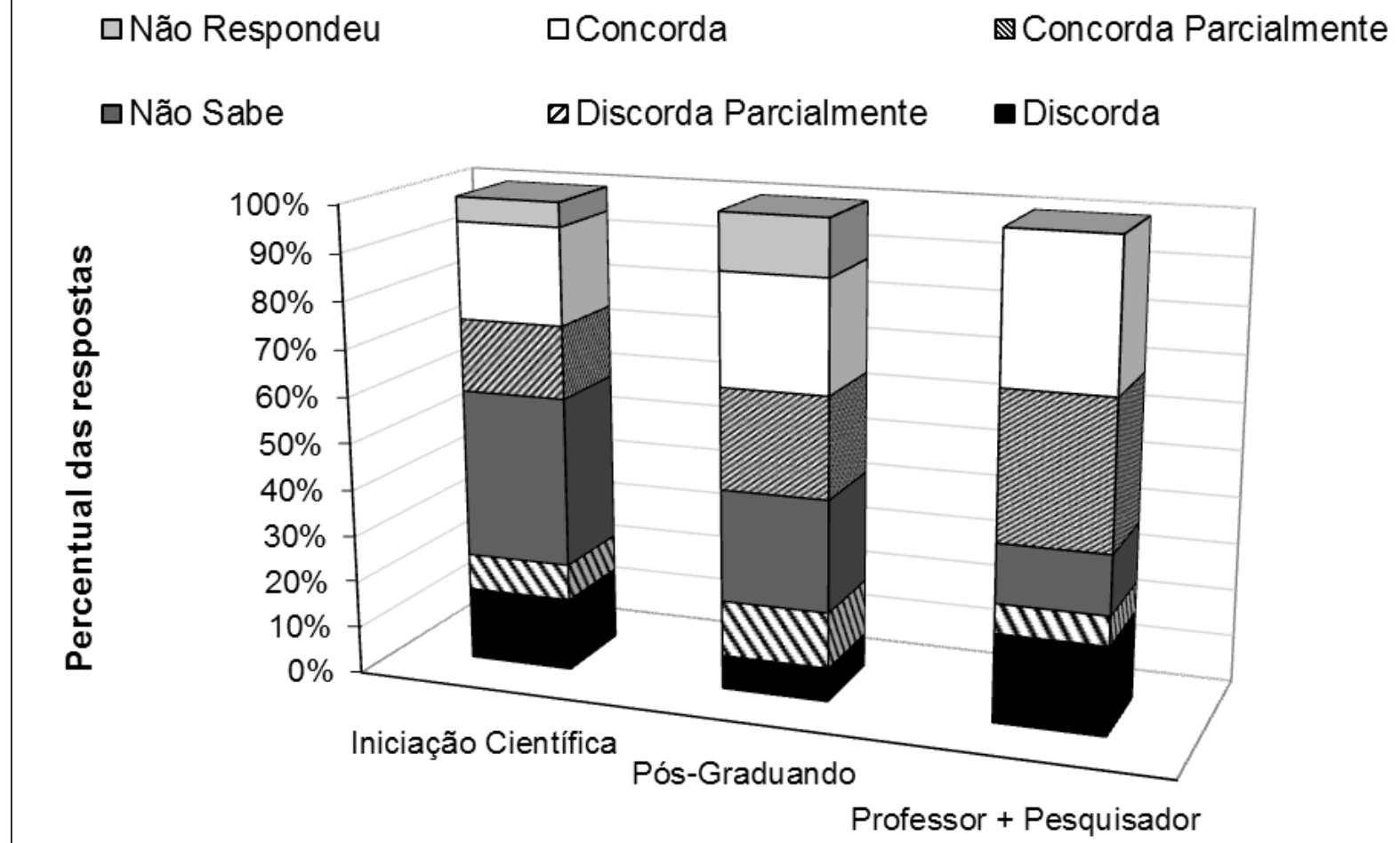

Figura 2. Respostas (\%) ao excerto "É bem conhecido que a infecção com T. gondii pode afetar a cognição e o comportamento de roedores. (...) Estudos mais recentes levaram os pesquisadores a formular a hipótese de manipulação. Esta hipótese estabelece que o parasita pode alterar o comportamento de seus hospedeiros para aumentar sua taxa de transmissão. (...)" [13].

Em algumas respostas verificou-se a afirmação de que o excerto descreve o processo de evolução destes organismos, em outras, observou-se o questionamento do termo "manipulação" por implicar intencionalidade. Dentre os ICs que discordaram e justificaram sua opinião, a maioria questionou o termo "manipulação", como podemos observar: "Não é manipulação, é seleção natural."; "Não se trata de manipulação, o bicho não pensa." e "Não seria uma manipulação.".

Nas opiniões discursivas dos PGs que concordaram com o excerto podemos observar que a manipulação é justificada por eventos evolutivos, ou seja, a hipótese estaria de acordo com a teoria da evolução: "O que ocorre hoje é consequência do processo evolutivo que selecionou este comportamento em ratos, em sua interação com o parasita." e "Essa hipótese está de acordo com a teoria da evolução.".

Apesar dos questionamentos, muitos concordaram, concordaram parcialmente ou discordaram somente parcialmente. Essa postura pode ser explicada pelo possível reconhecimento de que o excerto provém de um artigo científico publicado. Apesar de não 
Identification of anthropomorphic, teleological and vitalist conceptions amongst participants of an annual meeting of SBBq

ter sido exposto o periódico utilizado, nem de identificarmos o título do artigo, esse fato poderia ser constatado através da presença do nome do autor e ano da publicação. Assim, não foi possível evitar totalmente o sugestionamento das respostas, como pretendido.

\section{3 "O objetivo de todos os organismos é viver"}

Em relação à frase "O objetivo de todos os organismos é viver", $12,8 \%$ dos ICs não souberam responder. De todas as frases e/ou excertos avaliados no estudo esse foi o menor índice de "Não sei" indicado pelos estudantes de iniciação científica. A maior parte das respostas foi de concordância entre estudantes de IC (56,4\%), PGs $(69 \%)$, PPs $(62,5 \%)$, com perfil de respostas similar entre todas as categorias (Figura 3). Ou seja, pesquisados que questionaram outros excertos, concordaram com este. Algumas respostas indicaram que o objetivo é a prevalência ou perpetuação dos genes em vez de "O objetivo de todos os organismos é viver". Respostas que indicam noções similares ("Perpetuar seus genes."; "Crescer e reproduzir-se (...)"; "Deixar descendentes."; “(...) se adaptar ao meio."; "Ou sobreviver.") apresentaram declarações tanto de "Concordo ou Concordo parcialmente" quanto "Discordo ou Discordo parcialmente", indicando que não foi identificado o caráter teleológico implícito na ideia de "objetivo".

Para os PPs, verificou-se um percentual similar que concordou com este excerto e também com o excerto de Ernst Mayr [4], que afirma o oposto: a seleção natural "não tem meta definida", ou seja, a sobrevivência (ou extinção) de uma espécie não é um objetivo no processo de seleção natural. Esta concepção científica é o oposto da noção teleológica presente na resposta de um dos estudantes de graduação: "A evolução leva a (sic) conservação da vida." 
Identification of anthropomorphic, teleological and vitalist conceptions amongst participants of an annual meeting of SBBq

\section{Objetivo dos organismos é viver}

$\begin{array}{lll}\square \text { Não Respondeu } & \square \text { Concorda } & \mathbb{N} \text { Concorda Parcialmente } \\ \square \text { Não Sabe } & \square \text { Discorda Parcialmente } & \text { Discorda }\end{array}$

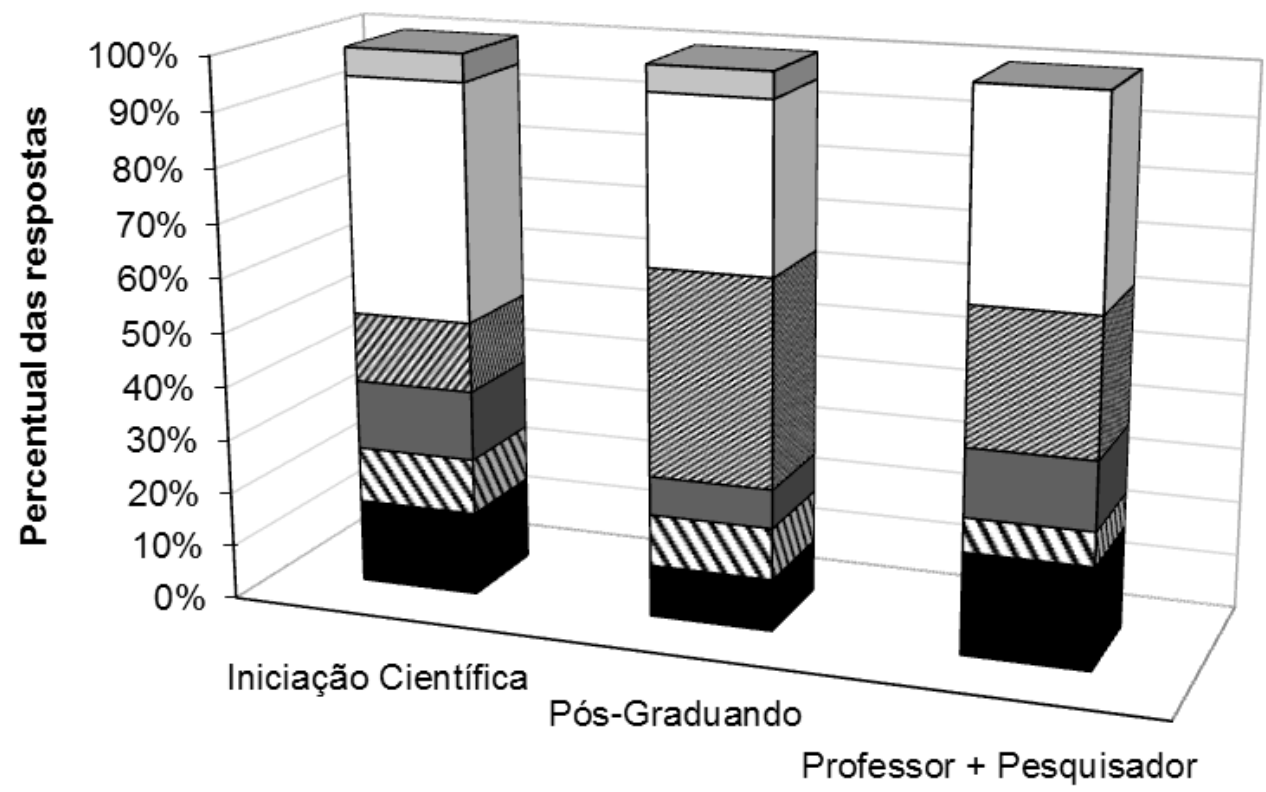

Figura 3. Respostas (\%) à afirmação "O objetivo de todos os organismos é viver".

A maior parte da discordância geral em relação à frase veio dos ICs: $25,6 \%$ discordaram ou discordaram parcialmente. Logo em seguida $25 \%$ dos PPs discordam e $19 \%$ dos PGs. Entre os ICs, houve respostas em que a existência de objetivos foi questionada. Como nas respostas: "Discordo. A afirmação apresenta 2 problemas. Primeiro, o uso da palavra 'objetivo' supõe uma teleologia para a vida, o que não é correto do ponto de vista científico (por não poder ser verificado ou sequer inferido de dados concretos). Segundo, a palavra 'viver' não é muito precisa, pois é amplamente usada em nossa língua em diferentes contextos, permitindo que a frase seja interpretada conforme a vontade do leitor."; "Concordo parcialmente. Acredito que a grande maioria dos organismos vivos não tenham (sic) consciência que estão vivos, ou de qualquer outra coisa, quanto mais um objetivo.".

A resposta de um estudante de iniciação científica questionou a visão teleológica na sentença, mas não notou que interpretações finalistas dos processos biológicos podem ter relação com o campo religioso: "Concordo. É uma visão teleológica, mas bem melhor que uma visão teológica ou religiosa." 
Identification of anthropomorphic, teleological and vitalist conceptions amongst participants of an annual meeting of SBBq

Vale destacar a resposta na qual um doutorando identificou o problema principal na sentença: "Discordo. Los organismos no tienen objetivo.". As respostas, mesmo aquelas que formalmente foram caracterizadas como discordâncias, apresentaram uma concepção teleológica, na definição proposta por Mayr [4] e uma concepção pragmática e unitária, segundo Bachelard [1]. É o caso das respostas dadas por professores/ pesquisadores apresentados no Quadro 3.

\subsection{Corrida armamentista}

O perfil de respostas ao excerto que descreve a ideia de "corrida armamentista" é apresentado na Figura 4.

\section{Corrida armamentista}

$\begin{array}{lll}\square \text { Não Respondeu } & \square \text { Concorda } & \mathbb{\$} \text { Concorda Parcialmente } \\ \square \text { Não Sabe } & \square \text { Discorda Parcialmente } & \text { aDiscorda }\end{array}$

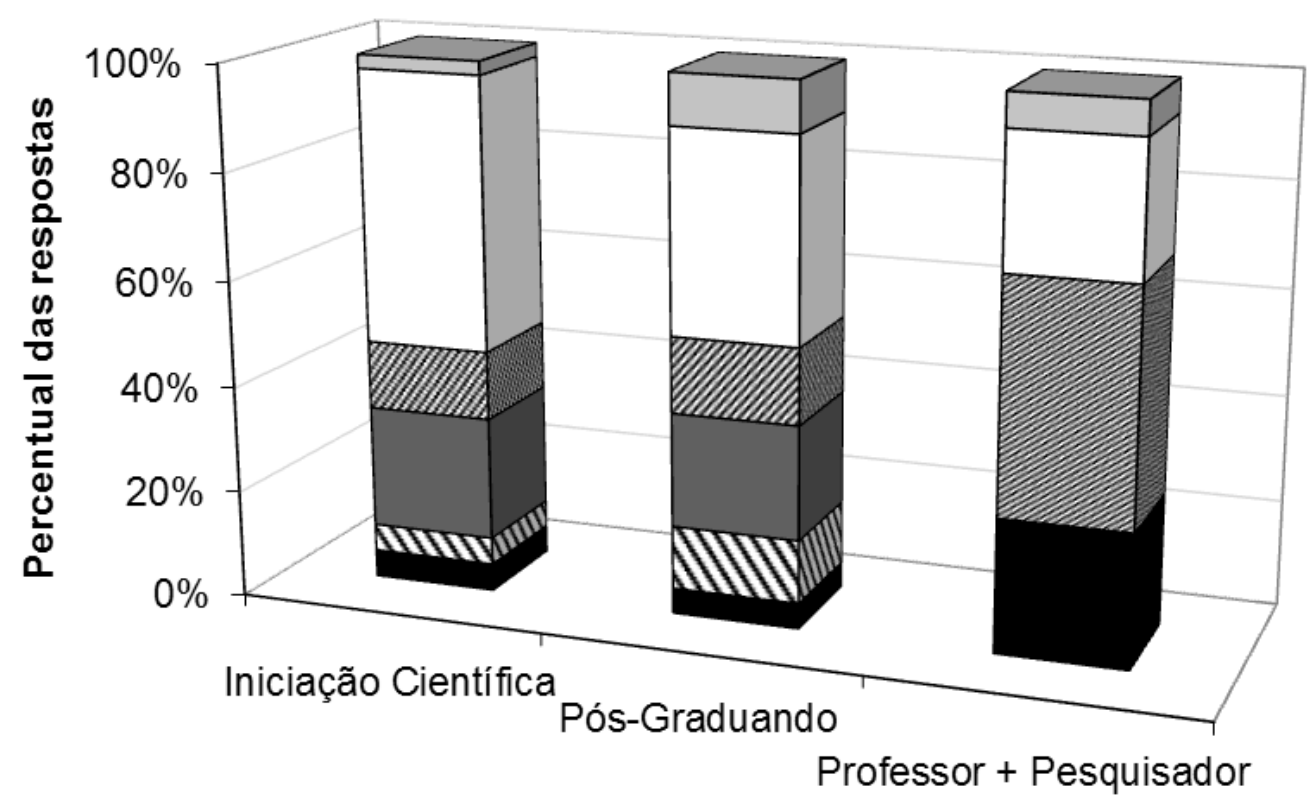

Figura 4. Respostas (\%) ao excerto "Muitas bactérias patogênicas escondem-se e crescem em compartimentos intracelulares ligados à membrana, chamados fagossomos, onde elas são protegidas do sistema imune e ainda recebem nutrientes da célula infectada. Esta situação coloca um problema para o hospedeiro. Desta forma a célula hospedeira toma medidas para destruir o patógeno, o qual, obviamente, tenta se defender. Em uma clássica "corrida armamentista" evolucionária, ambos, patógeno e células hospedeiras têm desenvolvido um arsenal de armas, e esta corrida certamente não está terminada ainda." [14]. 
Identification of anthropomorphic, teleological and vitalist conceptions amongst participants of an annual meeting of SBBq

A maior parte concorda com o trecho: aproximadamente $64 \%$ dos ICs, $52,4 \%$ dos PGs e $68,75 \%$ dos PPs. Entre os PPs, o maior percentual foi o de concordância parcial e muitos não explicaram em quais pontos houve objeção. Muitas respostas reforçaram o seu caráter teleológico, relacionando o processo ao fato dos organismos terem como objetivo viver ou perpetuar seus genes.

Dos excertos avaliados nesse estudo, esse foi o com menor discordância total, indicando que essa visão já é padrão em algumas explicações científicas. Apenas 10,2\% dos ICs, $16,7 \%$ dos PGs e $25 \%$ dos PPs discordaram dessa frase. Algumas respostas questionaram o caráter teleológico do excerto, como aquelas que questionaram a existência de um planejamento ('Parece que existe um 'planejamento' usando estes termos e não existe planejamento."), que as células tenham consciência ("Parasitas como as bactérias intracelulares não tem (sic) consciência (sic) e apenas evoluíram (sic) bioquimicamente para essa forma.") ou que as células tomam decisões ("Porque se trata de una situación fisiológica, las células no toman desiciones.").

Os termos foram também questionados, mesmo em concordâncias: “(...) não aplicaria estes termos p/ uma conceituação (sic) científica" e algumas respostas identificaram seu caráter antropomórfico: "Corrida armamentista é um termo/fenômeno completamente sociológico/antropológico. De forma nenhuma se aplica à situação em questão."e "(...) o homem tentando HUMANIZAR as relações naturais, os ciclos biológicos, e etc...". Outras respostas não identificaram os obstáculos antropomórfico, teleológico, vitalista e verbal presentes na afirmação, até por ser um jargão comumente usado na área, mas buscaram atribuir o texto aos mecanismos bioquímicos, fisiológicos ou moleculares relacionados, a exemplo da resposta de um mestrando: "Por exemplo, as interleucinas que possuem receptores de membrana inibidoras (sic) de alguns 'invasores'.".

\subsection{Patógenos traiçoeiros}

Com relação ao excerto que trata dos "patógenos traiçoeiros", também houve um maior percentual de concordâncias entre todas as categorias analisadas (Figura 5). Um percentual de $56,4 \%$ dos ICs, $45,2 \%$ dos PGs e $56,2 \%$ dos PPs concordaram de forma geral (concordaram e concordaram parcialmente). 
Identification of anthropomorphic, teleological and vitalist conceptions amongst participants of an annual meeting of $S B B q$

\section{Patógenos traiçoeiros}

$\begin{array}{lll}\square \text { Não Respondeu } & \square \text { Concorda } & \mathbb{N} \text { Concorda Parcialmente } \\ \square \text { Não Sabe } & \text { ■Discorda Parcialmente } & \text { Discorda }\end{array}$

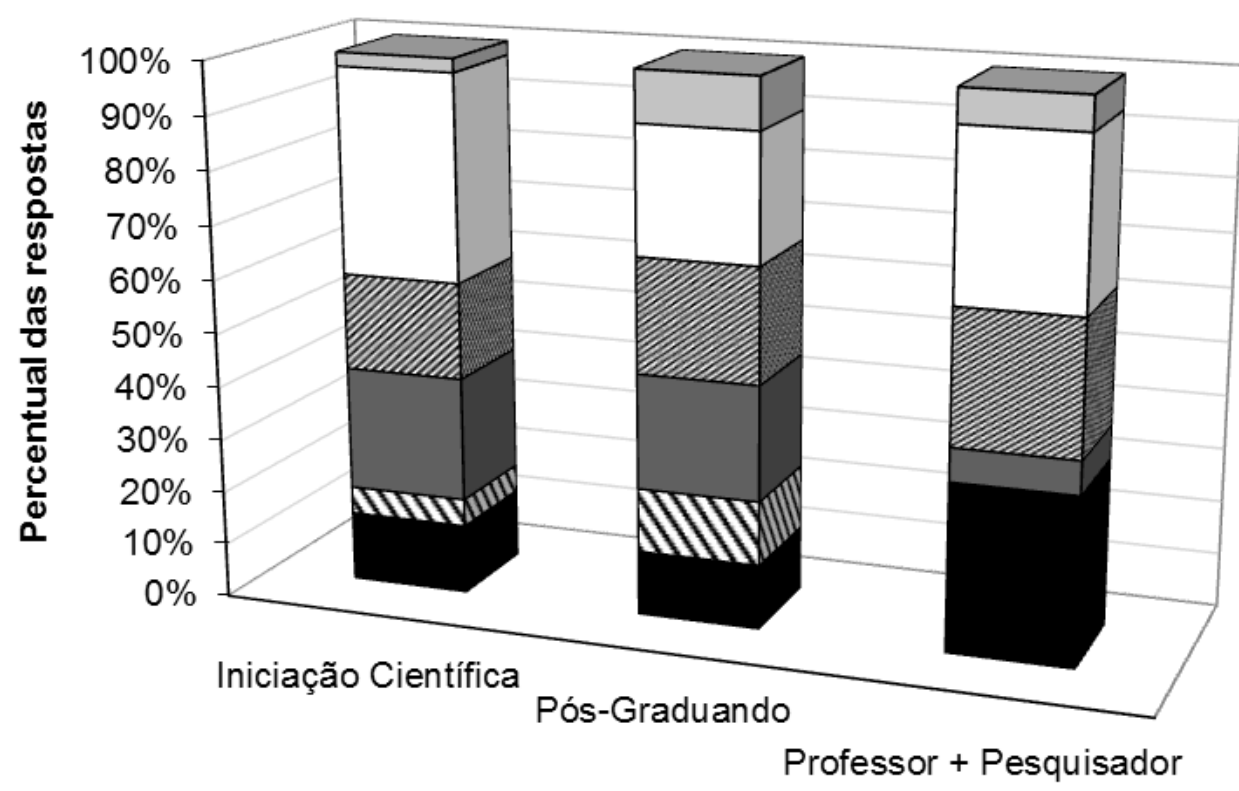

Figura 5. Respostas ao excerto (\%) "Parasitas intracelulares usam várias estratégias para invadir as células e subverter as rotas de sinalização celular e, assim, ganhar uma posição contra as defesas do hospedeiro. Entrada eficiente, habilidade para explorar nichos intracelulares, e persistência fazem destes parasitas patógenos traiçoeiros" [15].

Algumas respostas questionaram o termo empregado e alguns participantes identificaram o obstáculo epistemológico presente no excerto, mesmo sem nomeá-lo em termos bachelardianos ("'Traiçoeiro' é palavra usada para descrever comportamento humano, e não deve ser usada para descrever a ação de um microorganismo (sic) sobre o ambiente que habita (...)"; "Um ser que não possui consciência, não apresenta características de personalidade."; "Parasitas não pensam, seres unicelulares evolui (sic) ao acaso."; "Traiçoeiro para mim seria alguma ação indigna humana."; "São os seres humanos que ainda não descobriram uma melhor forma de trabalhar com ele."; "Esta seria uma atitude de um ser pensante."; "Termos que caracterizam comportamentos humanos (...)"; "Adjetivos com traiçoeiros só cabem a quem possui a faculdade cognitiva."; "A traição é um valor cultural e humano (...)"; "Patógenos (sic) não elaboram estratégias!"). Como em outras respostas, mesmo concordando, o termo foi questionado ("São traiçoeiros (sic) para o homem."; "Discordo da palavra traiçoeiro (sic).") ou explicado 
Identification of anthropomorphic, teleological and vitalist conceptions amongst participants of an annual meeting of SBBq

em termos bioquímicos/biológicos ("Co-evolução patógeno (sic) hospedeiro."; "Subvertem as rotas de sinalização."; "Evolução."; "A Leishmania e o tripanossoma, por exemplo, apresentam moléculas de membrana que suprimem o sistema imune (...)"; "Alguns patógenos passam a expressar genes de resistência à (sic) drogas por exemplo."). Isso indica que a forma de descrever um sistema biológico, empregando uma analogia, jargão, que configura um obstáculo verbal segundo Bachelard, é aceito na área. Isto foi resumido da seguinte forma por uma das respostas de um(a) mestrando(a): “(...) isso é apenas uma analogia!". Entretanto, muitas respostas não somente não questionaram seu caráter antropomórfico como reforçaram uma concepção teleológica destes processos, como na resposta: "Acredito que a evolução ensinou estes parasitas.".

O índice de discordância foi maior entre os PPs: aproximadamente $31,3 \%$. Esse índice cai para $18 \%$ entre os ICs e $23,8 \%$ entre os PGs. Entre os que discordam, estão as respostas: "(...) o termo traiçoeiro não pode ser aplicado a patógenos (sic)"; "A traição é um valor cultural e humano (sic) portanto ñ pertence ao mundo do patógeno."; e outras que apresentam uma concepção teleológica apesar da discordância: "Não se trata de ser 'traiçoeiro' e sim uma estratégia de sobrevivência e perpetuação."; "Apenas tentam se manter vivos de uma forma que o sistema do invasor não o (sic) reconheça.". Outras respostas questionaram o excerto, mas não formalmente: "Concordo parcialmente. Discordo da palavra traiçoeiro (sic)."; "Não sei. Isto é evolucionário (sic) na minha opinião.".

\section{6 "Microrganismos têm personalidade"}

Essa sentença que contém um obstáculo epistemológico explícito apresentou a maior parcela da discordância entre ICs e PPs, $51,2 \%$ e $68,7 \%$ respectivamente. A discordância geral entre os PGs foi relativamente menor, 19,5\% (Figura 6).

Entre os ICs, a discordância se expressou em respostas como: "Se tivessem eles teriam comunicação ou código reconhecível."; "Eles não são irracionais?! Não possuem sistema nervoso."; "O uso da palavra 'personalidade' não é adequado, pois se refere a uma característica (ou conjunto de características) tipicamente humana; portanto, não pode ser usada para descrever uma característica de microorganismos (sic), que não têm como apresentar 'personalidade' do modo como essa palavra é definida." 
Identification of anthropomorphic, teleological and vitalist conceptions amongst participants of an annual meeting of $S B B q$

\section{Microrganismos têm personalidade}

$\begin{array}{lll}\square \text { Não Respondeu } & \square \text { Concorda } & \mathbb{\text { COncorda Parcialmente }} \\ \square \text { Não Sabe } & \square \text { Discorda Parcialmente } & \square \text { Discorda }\end{array}$

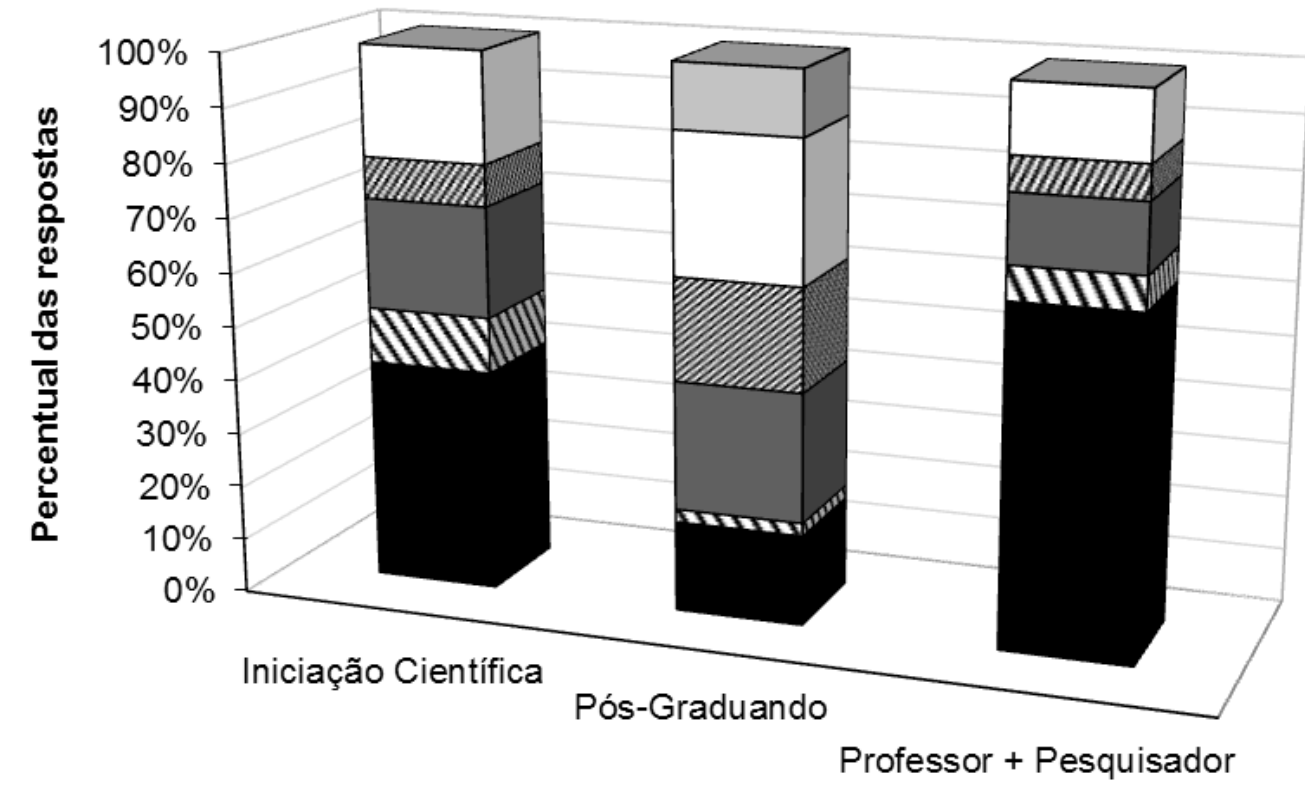

Figura 6. Respostas (\%) à sentença "Os microrganismos têm personalidade".

Dentre os grupos participantes, os PGs foram os que mais concordaram com essa assertiva: $45,2 \%$. Os ICs tiveram $28,2 \%$ de concordância e os PPs $18,7 \%$. Entre as concordâncias foram identificadas respostas com concepções antropomórficas e vitalistas ao comparar personalidade ao fenótipo dos microrganismos, características bioquímicas/genéticas ou pela expressão de seus genes: "Os microrganismos têm fenótipos que podem ser interpretados como personalidade dependendo do envolvimento que o pesquisador tem com seu objeto/ferramenta de pesquisa."; "Se personalidade envolver características bioquímicas/genéticas próprias.”; “A 'personalidade' é dada pela expressão de genes que permitem a ele ter ou não personalidade.”.

Entre o menor percentual que concordou, estão respostas que reforçam uma concepção (ou uma linguagem) antropomórfica e uma visão teleológica do processo de adaptação ao meio: "Pode ser uma tomada de decisão que levará a uma adaptação mais favorável ao organismo."; "Conseguem perceber o ambiente e mudar suas atividades gerais de acordo com a situação."; "Certamente eles se aproveitam do meio e de outros microrganismos para sobreviver com eficiência a situações inóspitas. Sofrem mutações, agregam material genético e assim se tornam eficientes.". 
Identification of anthropomorphic, teleological and vitalist conceptions amongst participants of an annual meeting of SBBq

Mesmo entre os participantes que afirmaram não saber opinar (20,5\% ICs; $23,8 \%$ PGs; $12,5 \%$ PPs) foram verificadas respostas que tendiam a questionar o termo "personalidade", como exemplo: "Nunca pensei sobre isso. Mas parece que personalidade é algo muito humano e que tentamos por (sic) esta característica (sic) em todos e tudo.". Outras respostas tendiam a aceitá-lo: "Cada organismo, micro ou não, tem sua (sic) peculiaridades, exigências e necessidades.”; “(..) se a ideia aqui for dizer que os microrganismos têm (sic) características próprias só deles, então eu concordo!".

\section{Discussão}

Foi possível identificar concepções antropomórficas e vitalistas nas respostas dos estudantes de iniciação científica, pós-graduandos, professores e pesquisadores ao questionário. Foi identificada uma visão teleológica/finalista do processo de evolução em afirmações como a existência de objetivos/finalidades na adaptação dos organismos. Tendencialmente, os professores e pesquisadores posicionaram-se em maior percentual em todas as respostas (menor número de respostas: "Não sei” ou abstenções em relação aos estudantes e pós-graduandos), com exceção daquelas atribuídas à frase "O objetivo de todos os organismos é viver". Entretanto, observou-se também a presença destas concepções vitalistas e teleológicas, muitas vezes de forma muito similar às demais categorias.

As afirmações teleológicas identificadas em muitas respostas corroboram os argumentos de Mayr [4] e de Bachelard [1] de que se caracterizam como obstáculos ao conhecimento científico. Segundo Bachelard [1], o obstáculo pragmático e unitário se expressa na associação entre verdade e utilidade, segundo a qual não é possível conceber um fenômeno que não seja "útil" na Natureza. Mayr [4] discute que não há nenhum apoio para a teleologia na teoria de Darwin apresentada em "Origem das Espécies" (ainda que em correspondências, particularmente em seus últimos anos, ele tenha sido por vezes descuidado com sua linguagem). Depois que Darwin estabeleceu o princípio da seleção natural, esse processo foi amplamente interpretado como teleológico (tanto por adeptos quanto por opositores); a evolução era com frequência considerada um processo teleológico porque levaria a um "melhoramento" ou "progresso". Entretanto, esta visão deixa de ser razoável quando se considera a natureza variacional da evolução darwiniana, que não tem meta final e (re) começa a cada nova geração. A evolução leva frequentemente a "becos sem saídas fatais" e resultam num "movimento irregular em 
Identification of anthropomorphic, teleological and vitalist conceptions amongst participants of an annual meeting of SBBq

zigue-zague na mudança evolutiva" (...) "É lamentável que alguns autores, mesmo na literatura mais recente, pareçam dotar a evolução de uma capacidade teleológica" [4]. As concepções teleológicas interferem na compreensão e na prática científica dos estudantes, pós-graduandos e até mesmo dos professores e pesquisadores, como mostrado nas respostas aos questionários. Considerando o conhecimento atual dos processos evolutivos, as concepções teleológicas agem como obstáculos ao avanço científico, não havendo motivos para a permanência do pensamento teleológico no processo de ensino que pode ser o principal responsável por estas concepções presentes entre cientistas e estudantes.

Temos discutido em nosso grupo de pesquisa que o campo religioso pode influenciar na interpretação finalista dada aos processos evolutivos, ou seja, a crença de que as modificações ocorrem sempre orientadas por uma força imaterial no sentido da perfeição em níveis mais elevados. No entanto, creditar essa interpretação finalista somente a uma elaboração equivocada ligada à religião é uma visão simplista demais. A visão finalista dos processos evolutivos encontra eco dentro do próprio pensamento biológico, conforme discutido anteriormente em Ribeiro e colaboradores [5]. No processo de aprendizagem, de acordo com Sepulveda e El-Hani [16], conforme ocorre o ensino da teoria darwinista da evolução, o conhecimento científico pode ser integrado às crenças religiosas e, através da criação de um modelo explicativo próprio, os conteúdos vão sendo elaborados e reorganizados pelos estudantes de forma a mantê-las. Segundo Porto e Falcão [17], a evolução biológica, da mesma forma que a origem da vida, por serem temas incorporados de forte influência cultural (particularmente religiosa) deveriam dispor de mais tempo e maior número de atividades escolares para serem melhor compreendidos.

Com relação às concepções antropomórficas discutidas na área, parece-nos mais razoável considerar que o antropomorfismo é uma manifestação teleológica onde os aspectos finalistas são direcionados às características humanizantes. Desta forma, identificamos que o antropomorfismo se insere na teleologia, e não o contrário como sugerido por Tamir e Zohar [7], pois existem explicações teleológicas que não são focadas em características humanizantes. É neste sentido que, ao buscarmos o desenvolvimento teórico do obstáculo do conhecimento unitário e pragmático proposto por Gaston Bachelard, chegamos à conclusão de que este se relacionava em alguns aspectos com a teleologia de Ernst Mayr, o que nos fez propor a noção do obstáculo teleológico [5]. Agora, 
Identification of anthropomorphic, teleological and vitalist conceptions amongst participants of an annual meeting of SBBq

tentando avançar mais na caracterização desta noção, nos parece que o aspecto do conhecimento unitário identificado por Bachelard está mais intimamente relacionado à influência de uma visão filosófica nas ciências, portanto mais diretamente ligado à teleologia caracterizada por Mayr. Já o antropomorfismo tem uma ligação mais próxima ao aspecto pragmático, do obstáculo caracterizado por Bachelard, por isso vamos caracterizá-lo como obstáculo antropomórfico.

Problematizando a noção de obstáculos epistemológicos, autores [2, 5, 10, 18, 19] discutem que o obstáculo epistemológico é um conhecimento, uma concepção e não uma dificuldade ou falta de conhecimento. Esse conhecimento é capaz de produzir respostas adaptadas a certos problemas, mas também produz respostas falsas em outros tipos de problema. Ele é um tipo de conhecimento que resiste às contradições com as quais é defrontado, bem como ao estabelecimento de um conhecimento melhor, isto é, apresenta resistência a modificações, caracterizando-se por se manifestar de forma recorrente. A rejeição desse conhecimento e a consequente superação do obstáculo levarão a um novo saber (conhecimento).

Desta forma, assim como não se pode ter uma visão unilateral dos obstáculos epistemológicos, é preciso perceber até que ponto as concepções representam um progresso para o conhecimento dos processos ao permitir uma explicação dos mesmos. É preciso identificar em qual estágio do desenvolvimento do conhecimento científico estas concepções passam a obstaculizar o desenvolvimento de conceitos mais precisos, sendo esta a preocupação principal de que trata a epistemologia de Bachelard, daí sua importância [5].

Ao avaliar as respostas às questões colocadas, é possível perceber que os obstáculos antropomórfico, teleológico e vitalista/animista estão presentes em conjunto com o obstáculo verbal (verbalismo) definido por Bachelard [1]. Os termos presentes nos excertos dos artigos científicos, como "hipótese de manipulação", "corrida armamentista" e "patógenos traiçoeiros" podem ser caracterizados como obstáculos verbais segundo Bachelard, muitas vezes utilizados sem que os cientistas se deem conta dos seus efeitos. O efeito deste obstáculo nas ciências é discutido por Marly Bulcão [20], divulgadora do pensamento bachelardiano em nosso país:

"Admitindo o desenvolvimento da ciência como descontínuo, com ruptura entre conhecimento passado e presente, a linguagem também deve ser retificada para se adequar aos novos conhecimentos. O processo de retificação da linguagem é mais lento 
Identification of anthropomorphic, teleological and vitalist conceptions amongst participants of an annual meeting of SBBq

que o da ciência, surgindo muitas vezes palavras que em lugar de expressarem os fenômenos são obstáculos à explicação científica. Metáforas são obstáculos que parecem simplificar a explicação científica, sugerindo diversas propriedades de uma substância, mas impedem construções mais precisas." [20]

Parece-nos que estas figuras de linguagem estão profundamente arraigadas nas concepções dos pesquisadores que responderam à pesquisa, fazendo com que não questionassem o seu uso nos excertos. O que também se torna um obstáculo ao desenvolvimento do conhecimento científico. Como discute Alice Casimiro Lopes [21], é possível inicialmente utilizar imagens, analogias e metáforas, mas é necessária a ruptura com estes obstáculos para avançar no processo de construção do conhecimento científico.

\section{Considerações finais}

Em um trabalho anterior [10], foram identificadas concepções teleológicas e vitalistas entre estudantes de pós-graduação em Bioquímica e foi enfatizada a necessidade de se incluir discussões epistemológicas em disciplinas da graduação, de forma a reduzir o impacto dessas concepções no desenvolvimento da pesquisa científica (elaboração de conceitos, formulação de experimentos, interpretação e discussão de resultados, etc...) por aqueles estudantes.

No entanto, o que se observa nos resultados obtidos e apresentados no presente artigo, é que tais concepções estão presentes mesmo entre os professores, i.e., aqueles que deveriam ser capazes de promover este necessário debate com os estudantes. Desta forma, identificou-se que tais discussões epistemológicas não devem se restringir à sala de aula, mas devem ser estimuladas na comunidade científica, através de palestras, simpósios e grupos de estudo dentro das unidades de pesquisa.

Devem necessariamente conter um debate sobre as diferenças entre 0 conhecimento comum e o processo de construção do conhecimento científico, além de promover um resgate da história da constituição de determinada disciplina (no caso, a Bioquímica) como uma disciplina científica, enfatizando-se como a produção de conceitos e teorias se fez de modo a eliminar ou minimizar a influência de tais concepções.

Além disso, acredita-se que seja fundamental discutir com os estudantes, professores e pesquisadores a importância da utilização de uma linguagem adequada 
Identification of anthropomorphic, teleological and vitalist conceptions amongst participants of an annual meeting of SBBq

para a boa compreensão dos processos bioquímicos/biológicos, percebendo-se os limites e perigos do emprego de metáforas e analogias.

Entende-se que é essencial discutir, principalmente com os alunos, a importância da leitura crítica independente do autor do texto. O ensino de Biologia, em particular de evolução através de seleção natural, precisa ser debatido, a formação científica dos professores melhorada, e sua didática otimizada com o objetivo de desenvolver metodologias e instrumentos que minimizem ou contornem os obstáculos epistemológicos.

Desta forma, esperamos com este trabalho contribuir para um debate necessário relacionado à construção e desenvolvimento do conhecimento científico, em particular na Bioquímica e áreas correlatas.

\section{Referências}

[1] Bachelard G. A Formação do Espírito Científico: contribuição para uma psicanálise do conhecimento. Rio de Janeiro: Contraponto; 1996.

[2] Brousseau G. Epistemological obstacles and problems in mathematics. In Balacheff N, Cooper M, Sutherland R, Warfield V (Edition and translation). Theory of didactical situations in mathematics. New York: Kluwer Academic Publishers; 2002. p.79-98.

[3] Pécheux M, Fichant M. Sobre a História das Ciências. Lisboa: Editorial Estampa; 1971.

[4] Mayr E. Biologia, Ciência Única: reflexões sobre a autonomia de uma disciplina científica. São Paulo: Companhia das Letras; 2005.

[5] Ribeiro MGL, Larentis AL, Caldas LA, Garcia TC, Terra LL, Herbst MH, Almeida RV. On the debate about teleology in Biology: the notion of "teleological obstacle". História, Ciências, Saúde - Manguinhos 2015; 22(4): 1321-1333.

[6] Looft, WR, Bartz, WH. Animism revived. Psychological Bulletin 1969; 71(1): 1-19.

[7] Tamir P, Zohar A. Anthropomorphism and teleology in reasoning about biological phenomena. Science Education 1991; 75(1): 57-67.

[8] Taber KS, Watts, M. The secret life of the chemical bond: students' anthropomorphic and animistic references to bonding. International Journal of Science Education 1996; 18(5): 557-568.

[9] Kallery M, Psillos D. Anthropomorphism and Animism in Early Years Science: Why Teachers Use Them, how They Conceptualise Them and What Are Their Views on Their Use. Research in Science Education 2004; 34: 291-311.

[10] Larentis AL, Ribeiro MGL, Paiva LMC, Caldas LA, Herbst MH, Moura MVH, Domont GB, Almeida RV. Obstáculos epistemológicos entre pós-graduandos de bioquímica. Ciências \& Cognição 2012; 17(2): 76-97.

[11] Larentis, A. L., Caldas, L. A., Ribeiro, M. G. L., Herbst, M. H., Garcia, T. C., Nicolau, C., Trevisol, E., Einsfeldt, K., Castro, F., Girão, L. F. C., Andrade, R. A., Domont, G. B., Almeida, R. V.Vitalismo e teleologia na comunidade bioquímica brasileira: um estudo de caso In: VIII Encontro Nacional de Pesquisa em Educação em Ciências e I Congreso Iberoamericano de Investigación en Enseñanza de Las Ciencias, 2011, Campinas, SP. Anais do VIII ENPEC - I CIEC. ABRAPEC, p.1-12.

[12] Likert R. A Technique for the Measurement of Attitudes. Archives of Psychology 1932; 22(140): 1-55. 
Identification of anthropomorphic, teleological and vitalist conceptions amongst participants of an annual meeting of SBBq

[13] Yolken RH, Dickerson FB, Fuller TE. Toxoplasma and schizophrenia. Parasite Immunology 2009; 31(11): 706-715.

[14] Kuijl C, Neefjes J. New insight into the everlasting host-pathogen arms race. Nature Immunology 2009; 10(8): 808-809.

[15] Sibley LD. Intracellular Parasite Invasion Strategies. Science 2004; 304 (5668): 248-253.

[16] Sepulveda C, El-Hani CN. Quando visões de mundo se encontram: religião e ciência na trajetória de formação de alunos protestantes de uma licenciatura em ciências biológicas. Investigação em Ensino de Ciências 2004; 9(2): 137-175.

[17] Porto PR, Falcão EB. Teorias da origem e evolução da vida: dilemas e desafios no ensino médio. Ensaio: Pesquisa em Educação em Ciências 2011; 12: 13-30.

[18] Galli LMG, Meinardi EN. The Role of Teleological Thinking in Learning the Darwinian Model of Evolution. Evolution: EducationandOutreach 2011; 4: 145-152.

[19] Silva LA, Larentis AL, Caldas LA, Ribeiro MGL, Almeida RV, Herbst MH. Obstáculos Epistemológicos no Ensino-Aprendizagem de Química Geral e Inorgânica no Ensino Superior: Resgate da Definição Ácido-Base de Arrhenius e Crítica ao Ensino das "Funções Inorgânicas". Química Nova na Escola 2014; 36(4): 261-268.

[20] Bulcão M. Racionalismo da Ciência Contemporânea. Uma Análise da Epistemologia de Gaston Bachelard. Rio de Janeiro: Edições Antares; 1981.

[21] Lopes AC. Currículo e Epistemologia. ljuí: Editora Unijuí; 2007.

\section{Agradecimentos}

À Sociedade Brasileira de Bioquímica e Biologia Molecular (SBBq), especialmente à Cynthia Sayuri Bando, pelo auxílio na distribuição dos questionários entre os participantes da XXXIX Reunião Anual, ocorrida de 18 a 21 de maio de 2010 em Foz do Iguaçu, Paraná, Brasil. Este trabalho se beneficiou das discussões na disciplina Lógica e Filosofia da Ciência do Instituto de Química da UFRJ. Os autores agradecem aos estudantes Carolina Nicolau, Eduardo Trevisol, Karen Einsfeldt, Frederico Castro, Luciana Facchinetti de Castro Girão, Rafael Alves de Andrade. Ao Professor Dr. Gilberto Barbosa Domont, por viabilizar a pesquisa junto à SBBq. 